\title{
Short communication: Cytokine profiles from blood mononuclear cells of dairy cows classified with divergent immune response phenotypes
}

\author{
C. E. Martin, ${ }^{\star} †$ M. A. Paibomesai, ${ }^{\star} \ddagger$ S. M. Emam, ${ }^{*}$ J. Gallienne, ${ }^{*}$ B. C. Hine,§ K. A. Thompson-Crispi, ${ }^{*} \#$ \\ and B. A. Mallard*\# ${ }^{1}$ \\ *Department of Pathobiology, Ontario Veterinary College, and \\ †Department of Molecular and Cellular Biology, University of Guelph, Guelph, ON, N1G 2W1, Canada \\ ‡Ontario Ministry of Agriculture, Food and Rural Affairs, Guelph, ON, N1G 4Y2, Canada \\ $\S C S I R O$, Animal, Food \& Health Sciences, Armidale, NSW, Australia \\ \#Center for Genetic Improvement of Livestock, University of Guelph, Guelph, ON, N1G 2W, Canada
}

\section{ABSTRACT}

Genetic selection for enhanced immune response has been shown to decrease disease occurrence in dairy cattle. Cows can be classified as high $(\mathrm{H})$, average, or low responders based on antibody-mediated immune response (AMIR), predominated by type- 2 cytokine production, and cell-mediated immune response (CMIR) through estimated breeding values for these traits. The purpose of this study was to identify in vitro tests that correlate with in vivo immune response phenotyping in dairy cattle. Blood mononuclear cells (BMC) isolated from cows classified as H-AMIR and H-CMIR through estimated breeding values for immune response traits were stimulated with concanavalin A (ConA; Sigma Aldrich, St. Louis, MO) and gene expression, cytokine production, and cell proliferation was determined at multiple time points. A repeated measures model, which included the effects of immune response group, parity, and stage of lactation, was used to compare differences between immune response phenotype groups. The H-AMIR cows produced more IL- 4 protein than $\mathrm{H}$-CMIR cows at $48 \mathrm{~h}$; however, no difference in gene expression of type-2 transcription factor GATA3 or IL4 was noted. The BMC from H-CMIR cows had increased production of IFN- $\gamma$ protein at 48, 72, and $96 \mathrm{~h}$ compared with H-AMIR animals. Further, H-CMIR cows had increased expression of the IFNG gene at 16, 24, and $48 \mathrm{~h}$ post-treatment with ConA, although expression of the type-1 transcription factor gene TBX21 did not differ between immune response groups. Although proliferation of BMC increased from 24 to $72 \mathrm{~h}$ after ConA stimulation, no differences were found between the immune response groups. Overall, stimulation of $\mathrm{H}-$ AMIR and H-CMIR bovine BMC with ConA resulted in distinct cytokine production profiles according to

Received February 10, 2015.

Accepted October 23, 2015.

${ }^{1}$ Corresponding author: bmallard@ovc.uoguelph.ca genetically defined groups. These distinct cytokine profiles could be used to define disease resistance phenotypes in dairy cows according to stimulation in vitro; however, other immune response phenotypes should be assessed.

Key words: blood mononuclear cells, dairy cows, type- 1 and type- 2 cytokines, immune response

\section{Short Communication}

Genetic selection using measurable phenotypic immune response (IR) traits has been proposed as a candidate for improving the overall health of livestock (Mallard et al., 2011, 2015; Thompson-Crispi et al., 2012a). In dairy cattle, the selection for increased milk production traits has been associated with increased occurrence of both metabolic and infectious diseases (Van Dorp et al., 1998; Fleischer et al., 2001; Koeck et al., 2013; Pritchard et al. 2013; Hagiya et al., 2014) and a negative effect on reproduction (Pryce et al., 2004). Recent research indicates that dairy cattle can be classified as high $(\mathbf{H})$, average, or low responders based on their type-1 cell-mediated immune response (CMIR) and type-2 antibody-mediated immune response (AMIR) through EBV (Heriazon et al., 2011; Hine et al., 2012; Thompson-Crispi et al., 2013). Both AMIR and CMIR have been demonstrated to be heritable, indicating it is possible to select for improved immune responsiveness (Thompson-Crispi et al., 2012b; Heriazon et al., 2013). Cows possessing a robust or $\mathrm{H}$ immune response have a decrease in disease occurrences for both metabolic and infectious diseases (ThompsonCrispi et al., 2012a, 2013). Therefore, as these branches of the IR provide protection against diverse pathogens, selection for robust and balanced CMIR and AMIR is expected to confer broad-based disease resistance to a range of pathogens (Abdel-Azim et al., 2005; Pinedo et al., 2009b; Thompson-Crispi et al., 2012a). In mammals, AMIR and CMIR are both genetically (Chaudhri et al., 2004; de Crean et al., 2005; Thompson-Crispi 
et al., 2012b; Filbey et al., 2014) and epigenetically regulated (Martino et al., 2011; Paibomesai et al., 2013; Scharer et al., 2013).

The CMIR are typically mounted to protect against intracellular pathogens. Representing the cellular responses, CMIR is predominated by the expression of inflammatory cytokine, such as IFN- $\gamma$ and IL-12, which is controlled by the transcription factor Tbox 21 (TBX21). The AMIR typically control and protect the host from extracellular pathogens (Estes and Brown, 2002; Zhu et al., 2010). The GATA binding protein 3 (GATA3) is a $\mathrm{T}_{\mathrm{H}} 2$ transcription factor which promotes production of AMIR cytokines, such as IL-4, IL-5, and IL-13. Both AMIR and CMIR are negatively correlated and evidence exists that these mechanisms are antagonistic to one another (Edwards, 2011; Kanno et al., 2012). Thus, the mechanisms of disease susceptibility of an individual could be explained, at least in part, through differences in cytokine profiles and transcription factor expression of $\mathrm{T}_{\mathrm{H}}$ cells and blood mononuclear cells (BMC).

The purpose of our study was to investigate whether a correlation between genetic parameters for immune response exists using in vitro testing methods to develop a rapid IR test. In the current study, cows are classified by assessment of overall AMIR and CMIR to a representative of an immune challenge and ranked based on IR-EBV. The groups are defined as having H-AMIR and low-CMIR (H-AMIR) or H-CMIR and low-AMIR (H-CMIR) as contrasting phenotypes. Individuals expressing these phenotypes were then used to investigate potential of using in vitro challenge of $\mathrm{BMC}$ to determine adaptive IR differences based on genetically defined groups. Immune responses were assessed by evaluating cytokine production by BMC and ability of BMC to proliferate.

Dairy cattle used in our study were previously categorized as $\mathrm{H}$, average, or low for AMIR and CMIR by assessing responses to type- 1 and type- 2 test antigens using the high immune response (HIR) technology (US Pat. No. 7258858; Wagter and Mallard, 2007; Hine et al., 2012). Briefly, 128 cows were immunized intramuscularly at d 0 with both a type- 1 and a type- 2 test antigen. Blood samples were collected at d 0 and 14 to evaluate antibody response to the type- 2 test antigen by ELISA. To assess CMIR, a delayed-type hypersensitivity test using the type- 1 test antigen was performed in the caudal fold of the tail. Estimated breeding values were determined for both AMIR and CMIR. Cows were ranked based on distance from the population mean; cows are considered H-IR at 1 standard deviation above the population mean, whereas L-IR are 1 standard deviation below (see Figure 1). All experimental procedures used in our study were approved by the University of
Guelph Animal Care Committee under the guidelines of the Canadian Council on Animal Care (CCAC, 1993). All animals showed no signs of clinical disease at the time of classification and at the time of sampling. Blood $(100 \mathrm{~mL})$ was collected from the coccygeal vein into EDTA-containing tubes (BD Vacutainer, Becton Dickinson, Franklin Lakes, NJ) and overlaid on Histopaque 1077 (Sigma Aldrich, St. Louis, MO) as per the manufacturer's instructions. Following centrifugation $(400 \times$ $g, 30 \mathrm{~min}$ at room temperature), BMC were collected, washed twice with PBS, and centrifuged again $(300 \times$ g, $13 \mathrm{~min}$ at room temperature). The BMC pellets were then resuspended in supplemented RPMI-1640 (Pathobiology Media Supply, Guelph, ON, Canada) containing $1 \%$ penicillin streptomycin (Pathobiology Media Supply), 10\% fetal bovine serum (Gibco, Burlington, ON, Canada), $2 \mathrm{~m} M$ L-glutamine, and $50 \mu M$ B-mercaptoethanol (Sigma Aldrich). Viable cells were stained with trypan blue (Sigma Aldrich) and quantified using a hemocytometer. Cells were diluted in supplemented RPMI to a final concentration of $2.5 \times 10^{6}$ cells $/ \mathrm{mL}$. For mRNA and cytokine protein quantification, $1 \mathrm{~mL}$ of BMC were seeded onto Costar 24-well flat-bottom plates (Corning Inc., Corning, NY) in quadruplicate for each time point (pooled after harvesting to show average gene expression and protein production). For BMC proliferation, $200 \mu \mathrm{L}$ of cells were plated onto Costar 96-well flat-bottomed plates (Corning Inc.) in sextet. The BMC were either treated with $5 \mu \mathrm{g} / \mathrm{mL}$ of concanavalin A (ConA; Sigma Aldrich) or remained untreated to act as controls. Cell culture supernatants were collected at $24,48,72$, and 96 h poststimulation and stored at $-20^{\circ} \mathrm{C}$ until analyzed for cytokine production. Cell proliferation was measured at 24, 48, 72, and $96 \mathrm{~h}$ poststimulation.

Interferon- $\gamma$ and IL-4 protein concentrations in cell culture supernatants were determined using the bovine IFN- $\gamma$ ELISA (Mabtech, Cincinnati, OH) and bovine IL-4 ELISA (Thermo Fisher Scientific, Nepean, ON, Canada) kits according to the manufacturer's instructions. The IFN- $\gamma$ ELISA (Mabtech) detection range was 5 to $500 \mathrm{pg} / \mathrm{mL}$ and the IL-4 ELISA detection range was 16 to $1,000 \mathrm{pg} / \mathrm{mL}$. Triplicates from all time points for each individual animal were run on the same plate. Numbers of samples from H-AMIR and H-CMIR animals were balanced on each plate. Plates were read using a scanning multiwell plate reader (Powerwave XS2, Biotek, Winooski, VT). Samples were repeated if the coefficient of variation between replicates were greater than $10 \%$. Cellular RNA was extracted from freshly cultured BMC at 4, 16, 24, and $48 \mathrm{~h}$ poststimulation using $1 \mathrm{~mL}$ of TRIzol per well (Invitrogen, Burlington, ON, Canada) and stored at $-80^{\circ} \mathrm{C}$ until analyzed for gene expression. The RNA 
was extracted from TRIzol per the manufacturer's protocol. Isolated RNA was treated with the Turbo-DNA free system (Ambion, Burlington, ON, Canada) per the manufacturer's instructions. Complementary DNA was prepared from $500 \mathrm{ng}$ of RNA using the Superscript III First Strand cDNA synthesis system (Invitrogen) per the manufacturer's instructions. Complementary DNA was stored at $-20^{\circ} \mathrm{C}$ before quantitative real-time PCR (qPCR) analysis. Primers for qPCR (Table 1) were designed using Primer3 primer design (NCBI; http:// www.ncbi.nlm.nih.gov/tools/primer-blast/) and Secondary Structure Estimation software (Integrated DNA Technologies, Coralville, IA); target product sizes were validated by running on a $2 \%$ agarose gel (data not shown). The qPCR was performed on the Roche Light Cycler480 II in 384-well plates (Roche, Mississauga, ON, Canada). Gene expression values were calculated using the Pfaffl fold-change equation (Pfaffl, 2001). Expression is represented as the difference or fold change

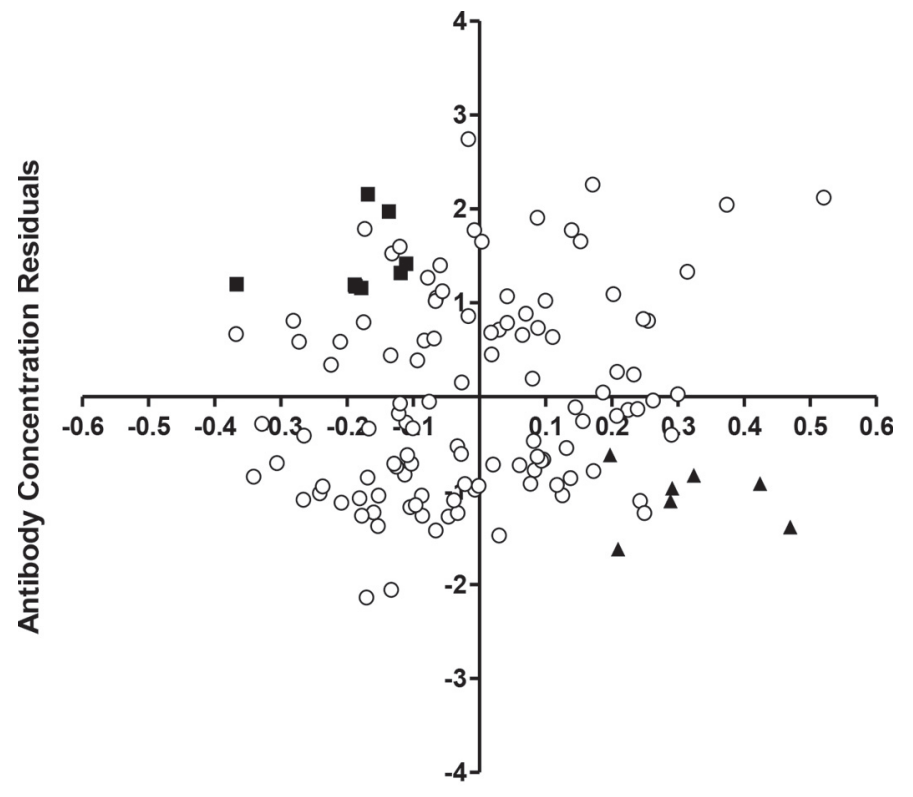

Skin Fold Thickness Residuals

Figure 1. Antibody-mediated immune response (AMIR) and cellmediated immune response (CMIR) phenotypic residuals of cows $(\mathrm{n}=$ 128) evaluated based on in vivo immune response to type 1 and type 2 antigens. Briefly, AMIR phenotype was based on increases in antibody concentrations from d 0 (time of inoculation) to d 14 after administration of type 2 test antigens. The CMIR phenotype was based on delayed-type hypersensitivity response at the tail fold to type 1 test antigen compared with a PBS control. Phenotypic residuals were used to determine high (H)-AMIR/low (L)-CMIR ( $(\boldsymbol{\Delta})$ and H-CMIR/L-AMIR (ם) groups for this study; the other immune response groups $(\bigcirc)$ are represented in this diagram but were not included in the molecular analysis. The H-AMIR cows are $1 \mathrm{SD}$ above the population mean for AMIR and 1 SD below the population mean for CMIR. The H-CMIR cows are $1 \mathrm{SD}$ above the population mean for CMIR and 1 SD below the population mean for AMIR. Phenotypic residuals are standardized and the population mean is represented at 0 on the $\mathrm{x}$ and $\mathrm{y}$-axis. between stimulated and unstimulated samples. These values are normalized based on the expression of the internal reference gene, $\beta$-actin, which was determined to be stably expressed in bovine BMC in our study and others (Meade et al., 2006; Robinson et al., 2007; Spalenza et al., 2011). Proliferation was quantified using the WST-1 cell proliferation assay kit (Roche) according to the manufacturer's instructions. Optical density values were read on the BioTek Powerwave XS2 multiwell plate reader. The proliferative stimulation index was calculated by subtracting the average of the media-controlled wells from the average of the 6 ConA-stimulated wells and dividing by the average of the 6 unstimulated wells at each time point for each animal. Data were analyzed independently using a general linear model that included repeated measures using PROC MIXED (SAS Version 9.2; SAS Institute, Cary, NC). The statistical model used was

$$
\mathrm{y}_{\mathrm{ijk} \mathrm{k}}=\mu+\mathrm{r}_{\mathrm{i}}+\mathrm{t}_{\mathrm{j}}+\mathrm{p}_{\mathrm{k}}+\mathrm{s}_{\mathrm{l}}+\varepsilon_{\mathrm{ijk} \mathrm{l}}
$$

where $\mathrm{y}=$ response vector of the observation; $\mu=$ overall mean; $r_{i}=$ immune response group (H-AMIR or $\mathrm{H}-\mathrm{CMIR}) ; \mathrm{t}_{\mathrm{j}}=$ time after stimulation $(24,48,72$, and $96 \mathrm{~h}) ; \mathrm{p}_{\mathrm{k}}=$ parity $(0,1$, or 2$) ; \mathrm{s}_{\mathrm{l}}=$ stage of lactation $(1$ $=$ not lactating, $2=1-80$ DIM, $3=81-235$ DIM, $4=$ $>235 \mathrm{DIM}$ ); and $\varepsilon=$ residual error. For each measure of immune response, nonsignificant effects and interactions $(P>0.2)$ were removed from the model.

The current study revealed different patterns of production of type- 1 and type- 2 IR mediators between genetically defined H-AMIR and H-CMIR cows. The H-CMIR cows had greater gene expression and protein production of the type- 1 cytokine IFN- $\gamma$, whereas $\mathrm{H}$ AMIR produced more IL-4 protein, a type-2 cytokine, in response to in vitro lymphocyte simulation by ConA. Although our study did not investigate direct cause and effect, susceptibility to disease has been related to cytokine profiles in other species (Lehmann et al., 2000; Ottenhoff et al., 2002; Chaudhri et al., 2004; Mortensen et al., 2004; Filbey et al., 2014). Therefore, it can be speculated from the current findings that cows that display a biased response to type-1- and type-2-specific antigens and possess differing cytokine profiles may also differ in responses to intracellular and extracellular pathogen infections. Potentially, the selected in vitro IR challenge tests could be used to identify IR phenotypes.

The H-CMIR cows had significantly greater IFN- $\gamma$ protein production at $48(P<0.05), 72(P<0.05)$, and $96 \mathrm{~h}(P \leq 0.01)$ poststimulation compared with H-AMIR cows (Figure 2A), with highest production at the $72 \mathrm{~h}$. Expression of the type-1 cytokine IFNG was greater in the H-CMIR group than H-AMIR cows at 
16, 24, and $48 \mathrm{~h}(P<0.05)$, with expression of the gene increasing before detection of the cytokine in cell culture supernatant (Figure 3C). In contrast, expression of IFNG in H-AMIR cows decreased from 4 to 16 h poststimulation $(P<0.05)$, but remained constant in H-CMIR group at the same peak time points. The expression of TBX21 was increased relative to control samples at the 4 to $48 \mathrm{~h}$ time points, peaking at 4 $\mathrm{h}$ poststimulation (Figure 2); however, no significant differences in TBX21 expression was noted between the groups (Figure 3A). Mice with aberrant IFN- $\gamma$ cytokine production are more susceptible to viral infections with increased morbidity and mortality, with infection rates twice that of their resistant counterparts that had normal IFN- $\gamma$ production (Chaudhri, et al., 2004).

Conversely, H-AMIR individuals had greater production of IL-4 protein than H-CMIR cows at 24, 48, and $72 \mathrm{~h}$ poststimulation, although the difference observed was only significant $(P<0.05)$ at $48 \mathrm{~h}$ (Figure $2 \mathrm{~B}$ ). No difference in expression of the type- 2 cytokine gene IL4 was observed between H-AMIR and H-CMIR. Expression of the type-2 transcription factor GATA3 was unaltered in response to ConA stimulation in both H-AMIR and H-CMIR individuals (Figure 3B). In comparison to type-1 cytokines, altered production of type-2 cytokines can increase susceptibility to extracellular pathogens, such as helminth or bacterial infections (Filbey, et al., 2014; Bruno et al., 2010). The elevated production of IL-4 in H-AMIR cows may help to provide protection of those cows to extracellular infections, such as those that commonly cause mastitis, as they would potentially possess a greater antibody mediated immune response. Thompson-Crispi et al., (2013) reported that cows with L-AMIR have higher incidence of mastitis caused by Escherichia coli, Staphylococcus aureus, Streptococcus spp., and other bacterial species compared with H-AMIR cows, whereas no significant differences were found with the CMIR trait.
Transcription factors TBX21 and GATA3 are known to inhibit the expression of each other through negative regulatory feedback pathways, leading to the differentiation of $\mathrm{T}$ cells into divergent lineages (Kanhere et al., 2012). Here, stimulation with ConA led to increased expression of TBX21 (Figure 1), which may have contributed to the inhibition of GATA3 expression and suggests that ConA is a mitogen that preferentially activates type- 1 responses in BMC. Regardless of this inhibition, and a subsequent lack of IL4 mRNA accumulation, H-AMIR individuals produced more IL-4 protein than their H-CMIR counterparts (Figure 3D). Transcription factor TBX21 could be playing a pivotal role in inhibiting $\mathrm{T}_{\mathrm{H}} 2$ differentiation through molecular competition that would not be detected with the techniques used in the current study. Downstream events following GATA3 and IL4 expression may lead to the divergent AMIR phenotypes, although little research thus far has focused on the mechanisms of $I L 4 \mathrm{mRNA}$ stability and subsequent production and secretion of IL-4. Given the diverse cell population found in BMC samples, it is possible that the difference between $\mathrm{H}$ CMIR and H-AMIR was too minor to detect. Isolation of specific CD8+ and CD4+ T-cells from the BMC population would offer higher resolution of TBX21 and GATA3 expression.

Evidence exists in various species that the ability of the host to produce appropriate AMIR and CMIR cytokine profiles can cause differences in disease susceptibility in connection to their cellular responses. Alteration in the hosts ability to produce, secrete, and recognize IFN- $\gamma$ is associated with disease susceptibility (Ottenhoff et al., 2002) and disease outcome, as shown in mice (Lehmann et al., 2000) and cattle (Bannerman et al., 2004; McGill et al., 2014). In cattle, a decrease in IFN- $\gamma$ production has been associated with increase susceptibility to Mycobacterium bovis (McGill et al., 2014), Mycobacterium avium ssp. paratuberulosis (Pine-

Table 1. Primer design $(\mathrm{F}=$ forward; $\mathrm{R}=$ reverse) and reaction conditions for real-time reverse transcription PCR gene expression experiments

\begin{tabular}{|c|c|c|c|c|c|c|}
\hline $\begin{array}{l}\text { Gene } \\
\text { symbol }\end{array}$ & Gene name & Sequence $5^{\prime}-3^{\prime}$ & $\begin{array}{l}\text { Amplicon } \\
\text { length (bp) }\end{array}$ & $\mathrm{T}_{\mathrm{a}},{ }^{1} \mathrm{C}^{\circ}$ & $\begin{array}{l}\text { PCR } \\
\text { slope }\end{array}$ & $\begin{array}{c}\text { PCR } \\
\text { efficiency }^{2}\end{array}$ \\
\hline$T B X 21$ & T-box 21 & $\begin{array}{l}\text { F: CGAGGACTATATACTGCCGC } \\
\text { R: CAAGACCACGTCCACATACA }\end{array}$ & 133 & 61 & -3.480 & 1.938 \\
\hline$I F N G$ & Interferon- $\gamma$ & $\begin{array}{l}\text { F: TATCTCAGGGGCCAACTAGG } \\
\text { R: CTGAAGCGCCAGGTATAAGG }\end{array}$ & 250 & 62 & -3.432 & 1.956 \\
\hline$A C T B$ & $\beta$-actin & $\begin{array}{l}\text { F: GCTTCTAGGCGGACTGTTAG } \\
\text { R: ACTTGGGAATGCTCGATCC }\end{array}$ & 254 & 62 & -3.493 & 1.933 \\
\hline
\end{tabular}

\footnotetext{
${ }^{1}$ Annealing temperature.

${ }^{2}$ Determined using quintet dilution series.
} 
do et al., 2009b), IMI of $S$. aureus (Bannerman et al., 2004; Kim et al., 2011), and E. coli (Bannerman et al., 2004). These differences in disease incidence could at least partly be due to genetic or epigenetic factors that

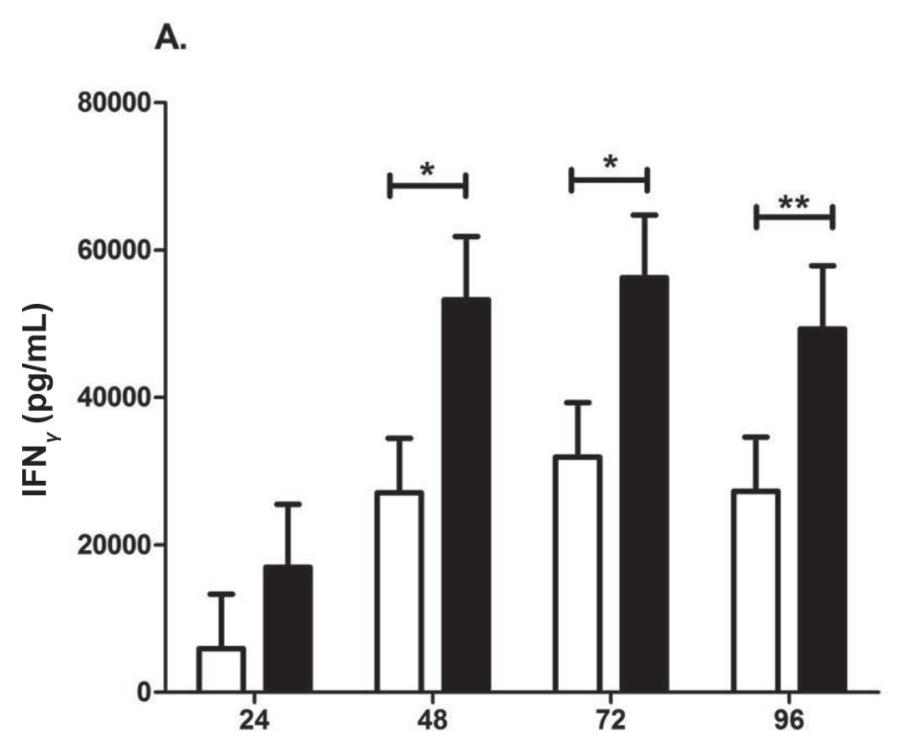

B.

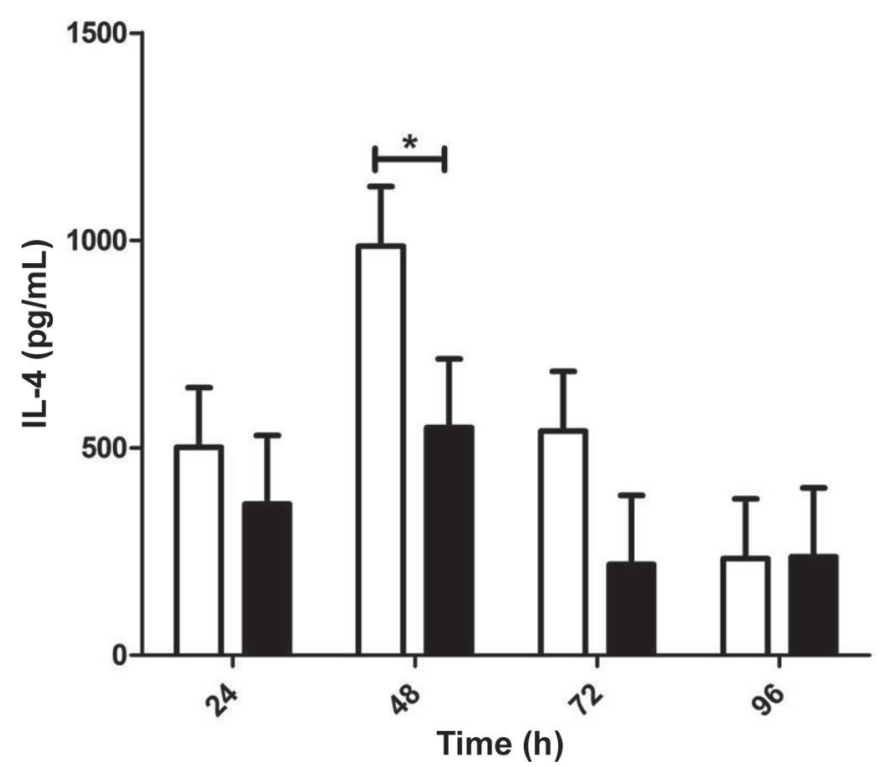

Figure 2. Interferon- $\gamma$ (A) and IL-4 (B) cytokine concentration $(\mathrm{pg} / \mathrm{mL})$ in supernatant from cultured high $(\mathrm{H})$-antibody-mediated immune response (AMIR; $\square, \mathrm{n}=8$ ) and $\mathrm{H}$-cell-mediated immune response (CMIR; $\mathbf{\square}, \mathrm{n}=7$ ) blood mononuclear cells stimulated with concanavalin A (5 $\mu \mathrm{g} / \mathrm{mL}$; Sigma Aldrich, St. Louis, MO). Concentrations were determined by sandwich ELISA and are reported as LSM \pm SEM. An asterisk (*) represents $P<0.05$, double asterisk $\left(^{* *}\right)$ represents $P \leq 0.01$. control type- 1 and type- 2 cytokine production either through differences in protein production or transcription factor binding. The divergent cytokine profiles observed in our study suggest that distinct type-1 and type-2 responses are important in regulating adaptive immune responses in bovine BMC from H-AMIR and H-CMIR dairy cows and could be used as a method for identifying IR biases.

Leukocyte populations differed between the H-AMIR and H-CMIR cows and are influenced by age and pregnancy status (Hine et al., 2012). The H-AMIR animals have proportionally higher B-cells both before and after immunization. In contrast, H-CMIR cows had greater proportion of $\gamma \delta$ T-cells than did H-AMIR animals before immunization, possibly influencing polarization of responses. Based on different leukocyte populations in these diverse H-AMIR and H-CMIR phenotypes, it was hypothesized that proliferation of subsets of BMC may vary between immune response groups. Proliferation of total $\mathrm{BMC}$ in response to ConA treatment did not differ between H-AMIR and H-CMIR individuals (Figure 4), suggesting that immune response phenotype is largely not influenced by the ability of BMC to expand in response to immune stimulation with a mitogen. Proliferation of specific subsets of BMC in response to ConA stimulation was not examined in the current study.

Collectively, these data indicate that upon in vitro mitogen stimulation, lymphocytes from the H-AMIR and H-CMIR phenotype cows have different type- 1 and type-2 cytokine production profiles. However, differential proliferation of $\mathrm{BMC}$ in response to stimulation was not observed between the immune response groups. The H-AMIR animals had increased production of the type2 cytokine IL-4, whereas H-CMIR individuals exhibited both increased production of the type- 1 cytokine IFN- $\gamma$ transcripts as well as IFN- $\gamma$ protein in response to stimulation, indicating that the H-AMIR and H-CMIR phenotype animals may have inherent biases in their cytokine production responses to a general stimuli, such as a mitogen. Differences between IR groups are most apparent at the cytokine protein level and could play a role in IR phenotype and disease susceptibility in dairy cattle. Our study provides evidence for methods in determining immune competency, which can be completed within $24 \mathrm{~h}$ of sampling based on peak expression of cytokine genes and cytokine secretion. The use of a mitogen in our study stimulated cell proliferation and cytokine production within $24 \mathrm{~h}$ of stimulation, but the tested mitogen could be eliciting a bias in the response; therefore, other antigens and mitogen should be tested to confirm results. In vitro IR testing is appealing when determining IR phenotypes, as it is more rapid than 
the current 2-wk test, less labor intensive on farm, and less invasive. The current study only tested cows with extreme IR biases to determine the feasibility of using an in vitro test for IR ranking. Future studies should include a larger population, including dairy cows that possess an average IR phenotype for both AMIR and CMIR. Nonetheless, it is likely that differentiating between closely related IR phenotypes of dairy cows solely with these in vitro methods would be difficult and still require cow-side IR phenotyping.
A.

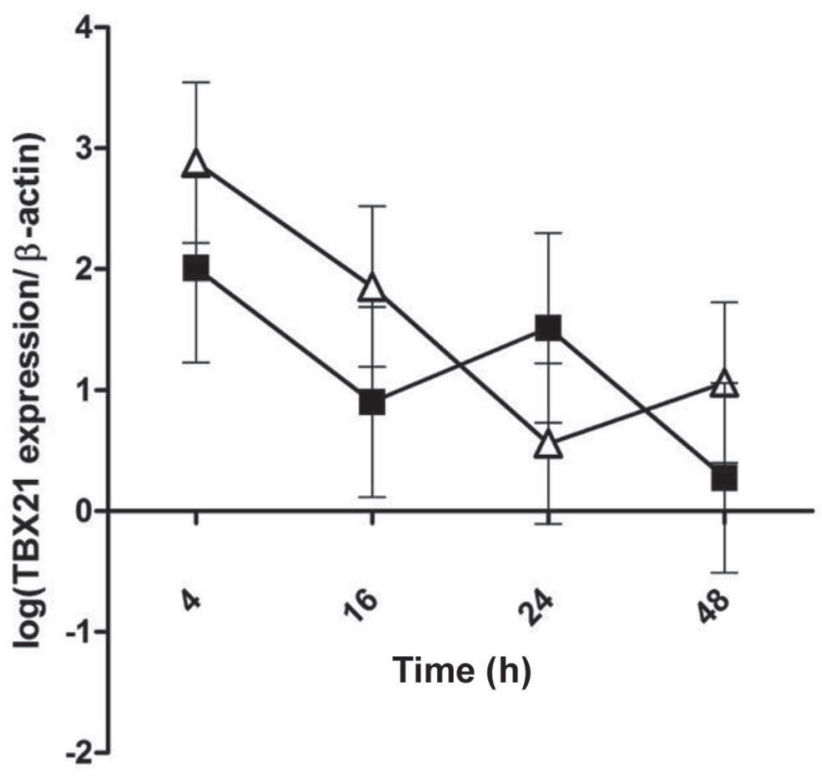

C.

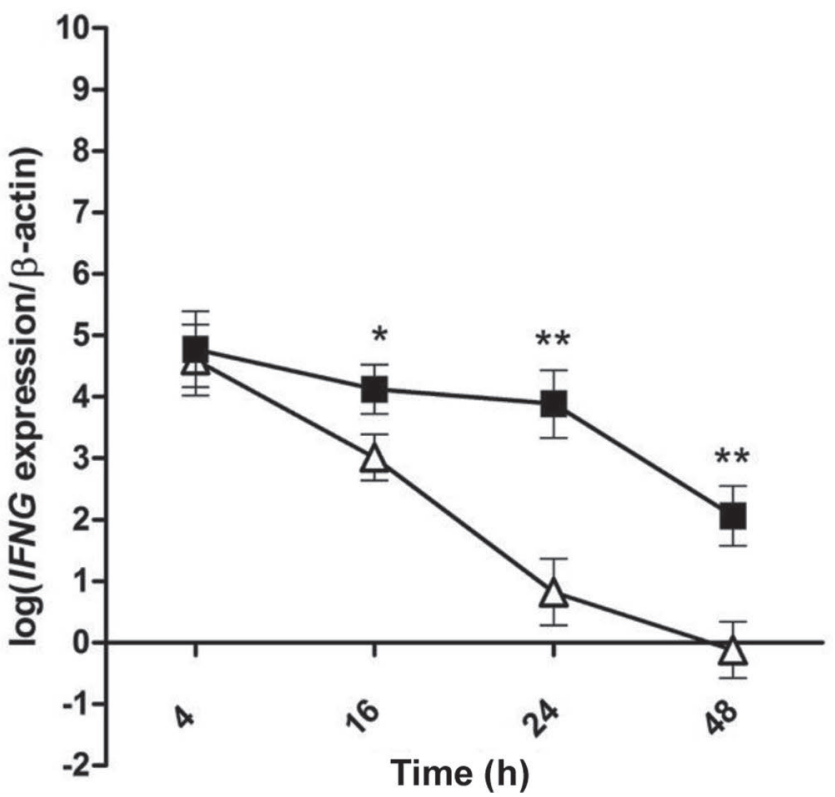

B.

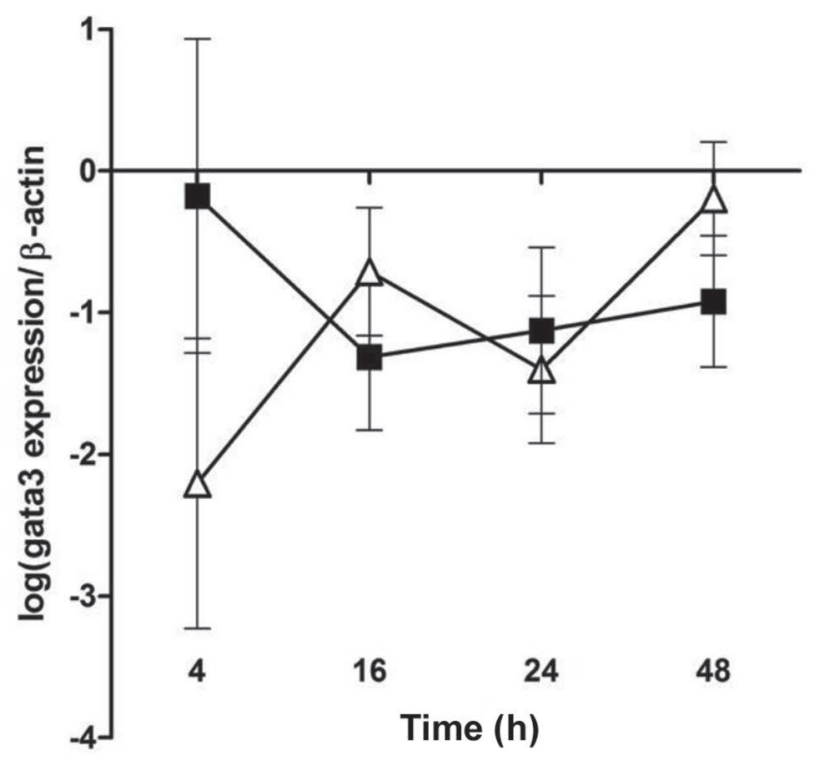

D.

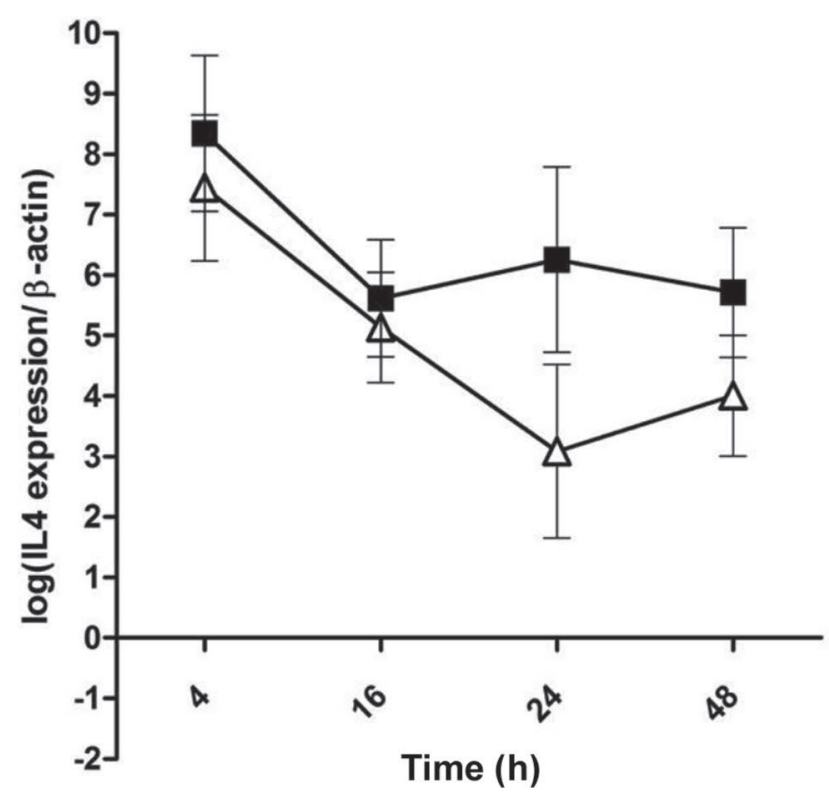

Figure 3. Fold change expression of TBX21 (A), GATA3 (B), IFNG (C), and IL4 (D) genes in high (H)-cell-mediated immune response (CMIR; $\boldsymbol{\square}, \mathrm{n}=7$ ) and H-antibody-mediated immune response (AMIR; $\Delta, \mathrm{n}=8$ ) groups after concanavalin A $(5 \mu \mathrm{g} / \mathrm{mL} ;$ Sigma Aldrich, St. Louis, MO) stimulation reported as LSM \pm SEM at 4, 16, 24, and $48 \mathrm{~h}$. Fold change expression is reported relative to unstimulated samples, normalized to the internal reference gene $A C T B$. An asterisk $\left(^{*}\right)$ represents $P<0.05$, double asterisk $\left(^{* *}\right)$ represents $P \leq 0.01$. 


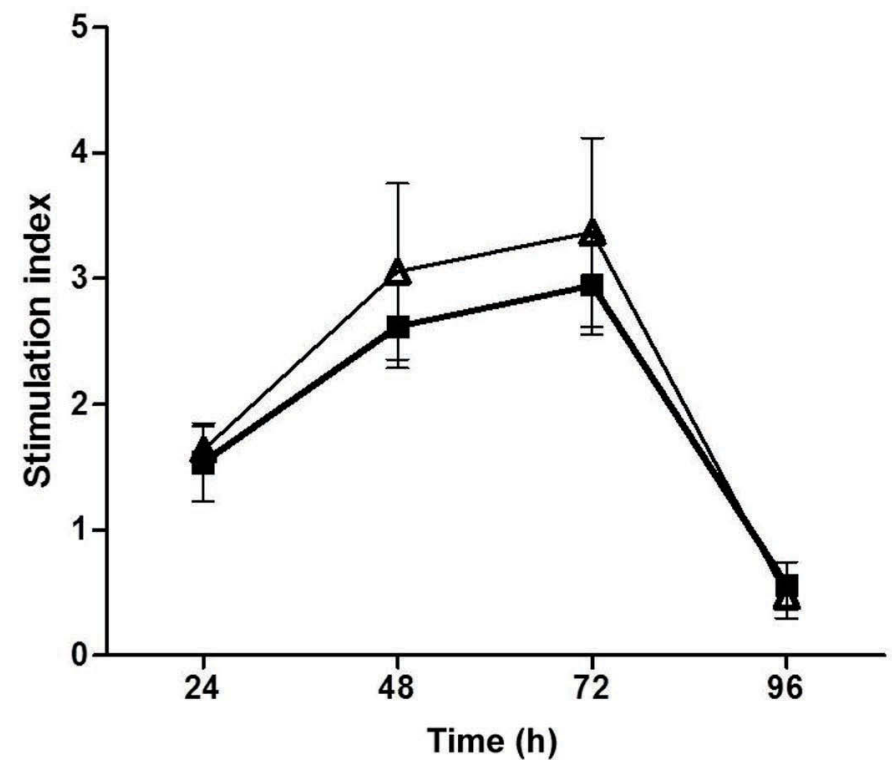

Figure 4. High $(\mathrm{H})$-antibody-mediated immune response (AMIR; $\Delta, \mathrm{n}=7$ ) and H-cell-mediated immune response (CMIR; $\mathbf{\square}, \mathrm{n}=8$ ) blood mononuclear cells proliferative stimulation index (stimulated absorbance or unstimulated absorbance) after concanavalin A treatment ( $5 \mu \mathrm{g} / \mathrm{mL}$; Sigma Aldrich, St. Louis, MO) as determined by the WST1 assay (Roche, Mississauga, ON, Canada); reported as LSM \pm SEM.

\section{ACKNOWLEDGMENTS}

We thank William Sears (University of Guelph, Guelph, ON, Canada) for statistical analysis support and the Elora Research Station staff (Elora, ON, Canada) for animal handling assistance. This research was financially supported by a Natural Science and Engineering Research Council of Canada grant to B. A. Mallard.

\section{REFERENCES}

Abdel-Azim, G. A., A. E. Freeman, M. E. Kehrli Jr., S. C. Kelm, J. L. Burton, A. L. Kuck, and S. Schnell. 2005. Genetic basis and risk factors for infectious and noninfectious diseases in US Holsteins. I. Estimation of genetic parameters for single diseases and general health. J. Dairy Sci. 88:1199-1207.

Bannerman, D. D., M. J. Paape, J. W. Lee, X. Zhao, J. C. Hope, and P. Rainard. 2004. Escherichia coli and Staphylococcus aureus elicit differential innate immune response following intramammary infection. Clin. Diagn. Lab. Immunol. 11:463-472.

Bruno, D. R., P. V. Rossitto, R. G. S. Bruno, M. T. Blanchard, T. Sitt, B. V. Yeargan, W. L. Smith, J. S. Cullor, and J. L. Stott. 2010 Differential levels of mRNA transcripts encoding immunologic mediators in the mammary gland secretions from dairy cows with subclinical environmental Streptococci infections. Vet. Immunol. Immunopathol. 138:15-24.

CCAC. 1993. Guide to Care and Use of Experimental Animals. Vol 1. 2nd ed. Canadian Council of Animal Care. Ottawa, ON.

Chaudhri, G., V. Panchanathan, R. M. L. Buller, A. J. M. van den Eertwegh, E. Claassen, J. Zhou, R. de Chazal, J. D. Laman, and G. Karupiah. 2004. Polarized type 1 cytokine response and cellmediated immunity determine genetic resistance to mousepox. Proc. Natl. Acad. Sci. USA 101:9057-9062. de Crean, A. J. M., D. Posthuma, E. J. Remarque, A. H. J. van den Biggelaar, R. G. J. Westendorp, and D. I. Boomsma. 2005. Heritability estimates of innate immunity: An extended twin study. Genes Immun. 6:167-170.

Edwards, E. 2011. Design CD8+ T-cell epitopes and the influence of peptide modification on the priming of antigen specific CD8+ Tcell responses (Doctoral dissertation). Immunology and Infection, QIMR Berghofer Medical Research Institute, Brisbane, Australia.

Estes, D. M., and W. C. Brown. 2002. Type 1 and type 2 responses in regulation of Ig isotype expression in cattle. Vet. Immunol. Immunopathol. 90:1-10.

Filbey, K. J., J. R. Grainger, K. A. Smith, L. Boon, N. van Rooijen, Y. Harcus, S. Jerkins, J. P. Hewitson, and R. M. Maizles. 2014. Innate and adaptive type 2 immune cell responses in genetically controlled resistance to intestinal helminth infection. Immunol. Cell Biol. 92:436-448.

Fleischer, P., M. Metzner, M. Beyerbach, M. Hoedemaker, and W. Klee. 2001. The relationship between milk yield and the incidence of some disease in dairy cows. J. Dairy Sci. 84:2025-2035.

Hagiya, K., T. Yamazaki, Y. Nagamine, K. Togashi, S. Yamaguchi, Y. Gotoh, T. Kawahara, Y. Masuda, and M. Suzuki. 2014. Genetic correlations between production and disease traits during first lactation in Holstein cows. Animal 8:217-223.

Heriazon, A., K. Hamilton, J. Huffman, B. N. Wilkie, W. Sears, M. Quinton, and B. A. Mallard. 2011. Immunoglobulin isotypes of lactating Holstein cows classified as high, average, and low type- 1 or -2 immune responders. Vet. Immunol. Immunopathol. 144:259269.

Heriazon, A., M. Quinton, F. Miglior, K. E. Leslie, W. Sears, and B. A. Mallard. 2013. Phenotypic and genetic parameters of antibody and delayed-type hypersensitivity responses of lactating Holstein cows. Vet. Immunol. Immunopathol. 154:83-92.

Hine, B. C., S. L. Cartwright, and B. A. Mallard. 2012. Analysis of leukocyte populations in Canadian Holsteins classified as high or low immune responders for antibody- or cell-mediated immune response. Can. J. Vet. Res. 76:149-156.

Kanhere, A., A. Hertweck, U. Bhatia, M. R. Gokmen, E. Perucha, I. Jackson, G. M. Lord, and R. G. Jenner. 2012. T-bet and GATA3 orchestrate Th1 and Th2 differentiation through lineage-specific targeting of distal regulatory elements. Nat. Commun. 3:1268.

Kanno, Y., G. Vahedi, K. Hirahara, K. Singleton, and J. J. O'Shea. 2012. Transcriptional and epigenetic control of $\mathrm{T}$ helper cell specification: Molecular mechanisms underlying commitment and plasticity. Annu. Rev. Immunol. 30:707-731.

Kim, Y., H. Atalla, B. Mallard, C. Robert, and N. Karrow. 2011. Changes in Holstein cow milk and serum proteins during intramammary infection with three different strains of Staphylococcus aureus. BMC Vet. Res. 7:51.

Koeck, A., F. Miglior, J. Jamrozik, D. F. Kelton, and F. S. Schenkel. 2013. Genetic association of ketosis and displaced abomasums with milk production traits in early first lactation of Canadian Holsteins. J. Dairy Sci. 96:4688-4696.

Lehmann, J., K. H. Enssle, I. Lehmann, A. Emmendorfer, and M. L. Lohmann-Matthes. 2000. The capacity to produce IFN-gamma rather than the presence of IL-4 determines the resistance and the degree of susceptibility to Leishmania donovani infection in mice. J. Interferon Cytokine Res. 20:63-77.

Mallard, B. A., H. Atalla, S. Cartwright, B. C. Hine, B. Hussey, M. Paibomesai, K. A. Thompson-Crispi, and L. Wagter-Lesperance. 2011. Genetic and epigenetic regulation of the bovine immune system: Practical implications of the high immune response technology. Pages 53-61 in Proc. National Mastitis Council 50th Annual Meeting. National Mastitis Council, Madison, WI.

Mallard, B. A., M. Emam, M. Paibomesai, K. Thompson-Crispi, and L. Wagter-Lesperance. 2015. Genetic selection of cattle for improved immunity and health. Jpn. J. Vet. Res. 63(Suppl. 1):S37S44.

Martino, D. J., M. K. Tulic, L. Gordon, M. Hodder, T. R. Richman, J. Metcalfe, S. L. Prescott, and R. Saffery. 2011. Evidence for agerelated and individual-specific changes in DNA methylation profile 
of mononuclear cells during early immune development in humans. Epigenetics 6:1085-1094.

McGill, J. L., R. E. Sacco, C. L. Baldwin, J. C. Telfer, M. V. Palmer, and W. R. Waters. 2014. The role of gamma delta T cells in immunity to Mycobacterium bovis infection in cattle. Vet. Immunol. Immunopathol. 159:133-143.

Meade, K. G., E. Gormley, S. D. Park, T. Fitzsimons, G. J. Rosa, E. Costello, J. Keane, P. M. Coussens, and D. E. MacHugh. 2006. Gene expression profiling of peripheral blood mononuclear cells (PBMC) from Mycobacterium bovis infected cattle after in vitro antigenic stimulation with purified protein derivative of tuberculin (PPD). Vet. Immunol. Immunopathol. 113:73-89.

Mortensen, H., S. S. Nielsen, and P. Berg. 2004. Genetic variation and heritability of the antibody response to Mycobacterium avium subspecies paratuberculosis in Danish Holstein cows. J. Dairy Sci. $87: 2108-2113$

Ottenhoff, T. H. M., F. A. W. Verreck, E. G. R. Lichtenauer-Kaligis, M. A. Hoeve, O. Sanal, and J. T. van Dissel. 2002. Genetics, cytokines and human infectious disease: lessons from weakly pathogenic mycobacterium and salmonellae. Nat. Genet. 32:97-105.

Paibomesai, M., B. Hussey, M. Nino-Soto, and B. A. Mallard. 2013. Effects of parturition and dexamethasone on DNA methylation patterns of IFN-gamma and IL-4 promoters in CD4+ T-lymphocytes of Holstein dairy cows. Can. J. Vet. Res. 77:54-62.

Pfaffl, M. W. 2001. A new mathematical model for relative quantification in real-time RT-PCR. Nucleic Acids Res. 29:e45.

Pinedo, P. J., C. D. Buergelt, G. A. Donovan, P. Melendez, L. Morel, R. Wu, T. Y. Langaee, and D. O. Rae. 2009a. Candidate gene polymorphisms (BoIFNG, TLR4, SLC11A1) as risk factors for paratuberculosis infection in cattle. Prev. Vet. Med. 91:189-196.

Pinedo, P. J., A. Donovan, O. Rae, and J. DeLapaz. 2009b. Association between paratuberculosis infection and general immune status in dairy cattle. Page 127 in Proc. 10th Int. Colloq. Paratuberculosis. http://www.paratuberculosis.info/index. php?view $=$ article\&id $=36$.

Pritchard, T., M. Coffey, R. Mrode, and E. Wall. 2013. Genetic parameters for production, health, fertility and longevity traits in dairy cows. Animal 7:34-46.
Pryce, J. E., M. D. Royal, P. C. Garnsworthy, and I. L. Mao. 2004. Fertility in the high-producing dairy cow. Livest. Prod. Sci $86: 125-135$.

Robinson, T. L., I. A. Sutherland, and J. Sutherland. 2007. Validation of candidate bovine reference genes for use with real-time PCR. Vet. Immunol. Immunopathol. 115:160-165.

Scharer, C. D., B. G. Barwick, B. A. Youngblood, R. Ahmed, and J. M. Boss. 2013. Global DNA methylation remodeling accompanies CD8 T cell effector function. J. Immunol. 191:3419-3429.

Spalenza, V., F. Girolami, C. Bevilacqua, F. Riondato, R. Rasero, C. Nebbia, P. Sacchi, and P. Martin. 2011. Identification of internal control genes for quantitative expression analysis by real-time PCR in bovine peripheral lymphocytes. Vet. J. 189:278-283.

Thompson-Crispi, K. A., B. Hine, M. Quinton, F. Miglior, and B. A. Mallard. 2012a. Short communication: Association of disease incidence and adaptive immune response in Holstein dairy cows. J. Dairy Sci. 95:3888-3893.

Thompson-Crispi, K. A., F. Miglior, and B. A. Mallard. 2013. Incidence rates of clinical mastitis among Canadian Holsteins classified as high, average and low immune responders. Clin. Vaccine Immunol. 20:106-112.

Thompson-Crispi, K. A., A. Sewalem, F. Miglio, and B. Mallard. 2012b. Genetic parameters of adaptive immune response traits in Canadian Holsteins. J. Dairy Sci. 95:401-409.

Van Dorp, T. E., J. C. M. Dekkers, S. W. Martin, and J. P. T. M. Noordhuizen. 1998. Genetic parameters of health disorders and relationships with 305-day milk yield and conformation traits of registered Holstein cows. J. Dairy Sci. 81:2264-2270.

Wagter, L., and B. A. Mallard, inventors. 2007. Method of Identifying High Immune Response Animals. University of Guelph, assignee. US Pat. No. 7,258,858.

Zhu, J., H. Yamane, and W. E. Paul. 2010. Differentiation of effector CD4 T cell populations. Annu. Rev. Immunol. 28:445-489. 